\title{
JEKK
}

Jurnal Epidemiologi Kesehatan Komunitas 2 (2), 2017, 89-98

\section{Faktor-Faktor yang Mempengaruhi Kejadian Kusta Pasca Kemoprofilaksis (Studi pada Kontak Penderita Kusta di Kabupaten Sampang)}

\author{
Elhamangto Zuhdan ", Kabulrachman ${ }^{* *}$, Suharyo Hadisaputro ${ }^{* * * *}$ \\ *Dinas Kesehatan Provinsi Jawa Tengah, ${ }^{* *}$ Fakultas Kedokteran Undip, ${ }^{* * *}$ Politeknik Kesehatan \\ Semarang
}

\begin{abstract}
Background : Leprosy (Morbus Hansen) is a chronic infectious disease caused by the bacterium Mycobacterium leprae. This disease is a type of granulomatous disease in the peripheral nerves and mucosa of the upper respiratory tract; and skin lesions are signs that can be observed from the outside. If left untreated, leprosy can be very progressive, causing damage to the skin, nerves, limbs, and eyes.

Methods : This research used case control study design 248 subjects selected by simple random sampling. The variables studied were age, sex, education level, occupation, BCG vaccination status, nutritional status, open wound history, chemoprophylaxis drug adherence, family economic condition, personal hygiene and home conditions. Data were analyzed using chi square test for bivariate test and multiple logistic regression.

Results : Duration of contact with patient ( $\mathrm{p}=0,050 ; \mathrm{OR}=1,88 ; 95 \% \mathrm{CI}=1,000-3,534), \mathrm{BCG}$ vaccination status $(\mathrm{p}=0,014 ; \mathrm{OR}=2,12 ; 95 \% \mathrm{CI}=1,161-3,881)$, nutritional status less $(\mathrm{p}=0,000$; $\mathrm{OR}=6.01 ; 95 \% \mathrm{CI}=3,188-11,331)$, open wound $(\mathrm{p}=0,002 ; \mathrm{OR}=0,37 ; 95 \% \mathrm{CI}=0,200-0,699)$, economic condition of low income family $(\mathrm{p}=0,000$; $\mathrm{OR}=3.07 ; 95 \% \mathrm{CI}=1,653-5,715)$. poor personal hygiene $(\mathrm{p}=0.001 ; \mathrm{OR}=2.99 ; 95 \% \mathrm{CI}=1.583-5.569)$.

Conclusion : Factors that have been proven to have an effect on the incidence of leprosy after chemoprophylaxis are low education level, $\geq 1$ year contact duration, poor nutritional status, poor family income economic condition and poor personal hygiene. Factors $\geq 1$ year contact duration, no grated BCG vaccination status, poor nutritional status, history of open wounds, poor family income economic condition and poor personal hygiene have probability of incidence leprosy were $90 \%$.
\end{abstract}

Keywords: Influence factors; incidence of leprosy post chemoprophylaxis theraphy; close contact of leprosy

Penulis korespondensi : elhamzuhdan@gmail.com 


\section{Pendahuluan}

Penyakit kusta (Morbus Hansen) adalah sebuah penyakit infeksi kronis yang disebabkan oleh bakteri Mycobacterium leprae jika tidak ditangani dapat menyebabkan kerusakan kulit, saraf, anggota gerak dan mata. ${ }^{1}$ Jalur penularan kusta sampai saat ini belum seluruhnya terungkap. Faktor risiko yang mempengaruhi kejadian kusta di antaranya yaitu kontak serumah dengan penderita kusta, kontak tetangga, kondisi kebersihan perseorangan yang buruk, pengetahuan, jenis kelamin, status vaksinasi BCG, dan kondisi sosio-ekonomi. ${ }^{2}$

Lebih dari 200.000 kasus kusta baru ditemukan setiap tahun di dunia. ${ }^{3}$ Wilayah dengan kasus tertinggi yaitu Asia Tenggara $(72,1 \%)$ dan Amerika (15,3\%). ${ }^{4}$ Indonesia telah mencapai target eliminasi kusta pada tahun 2000, namun 13 provinsi masih memiliki angka prevalensi lebih dari 1/10.000 penduduk. ${ }^{5}$ Penderita kusta di ASEAN 2,2\% dari Provinsi Jawa Timur. Prevalence Rate (PR) pada tahun 2016 sebesar 1,06 per 10.000 penduduk. Sebelas kabupaten/kota masih memiliki PR di atas 1/10.000 penduduk (high endemis), tertinggi ada di Sumenep (PR:4,38) diikuti Kabupaten Sampang (PR:3,69) dan paling rendah ada di Tulungagung (PR:0,06). ${ }^{6}$

Kemoprofilaksis adalah pemberian obat untuk mencegah infeksi, pada kusta mencegah infeksi $M$. leprae pada orang yang berisiko tinggi terpapar bakteri tersebut (kontak penderita). ${ }^{4}$ Kegiatan kemoprofilaksis telah dilakukan terhadap kontak penderita kusta sebanyak 15.848 orang $(94,55 \%)$ dari sasaran kontak sebesar dengan Case Detection Rate sebesar 35,55 per 100.000 penduduk. Proporsi wanita $41 \%$ proporsi anak $17 \%$ dari seluruh kasus baru, yang masih tinggi jika dibandingkan dari target sebesar kurang dari 5\%. ${ }^{6} 16.762$ orang di Kabupaten Sampang sejak April 2012-
Desember 2014. ${ }^{7}$ Tahun 2016 kasus di Kabupaten Sampang sebanyak 333 orang. Penelitian ini bertujuan mencari faktorfaktor yang mempengaruhi kejadian kusta pasca kemoprofilaksis.

\section{Metode}

Jenis penelitian yang dilakukan adalah penelitian observasional dengan menggunakan case control study untuk mengetahui beberapa faktor risiko kejadian kusta pasca kemoprofilaksis. Variabel bebas yang diteliti meliputi tingkat pendidikan, status vaksinasi BCG, status gizi, riwayat luka terbuka, kepatuhan minum obat kemoprofilaksis, kondisi ekonomi keluarga, kebersihan perorangan dan kondisi rumah.

Sampel kasus adalah penderita kusta yang didiagnosis petugas Dinas Kesehatan Sampang berdasarkan gejala klinis yang memenuhi kriteria inklusi dan eksklusi. Sampel kontrol adalah bukan penderita kusta yang memenuhi kriteria inklusi dan eksklusi. Jumlah sampel 248 dengan perbandingan kasus dan kontrol 1:1.

Sampel diambil secara systematic random sampling berdasarkan kasus terbanyak di Puskesmas kemudian dipilih berdasarkan interval. ${ }^{8}$ Instrumen yang digunakan adalah panduan kuesioner, alat ukur tinggi badan dan alat ukur berat badan. Data hasil penelitian dianalisis secara bivariat dan multivariat.

\section{Hasil Penelitian}

\section{Tingkat pendidikan terhadap kejadian kusta pasca kemoprofilaksis}

Proporsi responden alami kejadian kusta pada kelompok pendidikan rendah sebesar 59,7\% > dibanding responden pada kelompok pendidikan tinggi sebesar 40,3\%. Faktor tingkat pendidikan berpengaruh terhadap kejadian kusta 
( $\mathrm{p}=0,001 ;$ OR:2,27; 95\% CI: 1,363-3,766). Responden dengan tingkat pendidikan rendah berisiko 2,27 kali tertular penyakit kusta dibandingkan responden dengan tingkat pendidikan tinggi (Tabel 1).

\section{Kepatuhan minum obat terhadap kejadian kusta pasca kemoprofilaksis}

Proporsi responden alami kejadian kusta pada kelompok tidak patuh minum obat sebesar 51,6\% > dibanding responden pada kelompok patuh minum obat sebesar 48,4\%. Faktor kepatuhan minum obat berpengaruh terhadap kejadian kusta ( $\mathrm{p}=0,05$; OR: 1,63 ; 95\%CI: 0,987-2,702). Responden yang tidak patuh meminum obat kemoprofilaksis berisiko 1,63 kali tertular penyakit kusta dibandingkan responden yang patuh meminum obat kemoprofilaksis (Tabel 2).

\section{Lama kontak terhadap kejadian kusta pasca kemoprofilaksis}

Proporsi responden alami kejadian kusta pada kelompok kontak $\geq 1$ tahun sebesar 74,2\% > dibanding responden pada kelompok kontak $<1$ tahun sebesar 48,4\%. Faktor lama kontak berpengaruh terhadap kejadian kusta $(\mathrm{p}=0,035$; OR: 1,814 ; 95\%CI: 1,075 - 3,062). Responden yang lama kontak dengan penderita $\geq 1$ tahun berisiko 2,29 kali tertular penyakit kusta dibandingkan responden yang lama kontak $<1$ tahun (Tabel 3).

\section{Status vaksinasi BCG terhadap kejadian kusta pasca kemoprofilaksis}

Proporsi responden pada kelompok tidak ada parut BCG dan kelompok ada parut BCG masing-masing 50\%. Faktor status vaksinasi BCG merupakan faktor protektif terhadap kejadian kusta pasca kemoprofilaksis $\quad(\mathrm{p}=0,029 ; \quad$ OR: $\quad 0,57$; 95\%CI: 0,343-0,947) (Tabel 4).

\section{Status gizi terhadap kejadian kusta pasca kemoprofilaksis}

Proporsi responden alami kejadian kusta pada kelompok gizi buruk sebesar $74,2 \%>$ dibanding responden pada kelompok gizi baik sebesar $25,8 \%$. Faktor status gizi berpengaruh terhadap kejadian kusta ( $\mathrm{p}=0,001$; OR: 4,68; 95\%CI: 2,7258,022 ). Orang yang tergolong status gizi buruk berisiko 4,68 kali tertular penyakit kusta dibandingkan orang yang status gizinya baik (normal) (Tabel 5).

\section{Riwayat luka terbuka terhadap kejadian kusta pasca kemoprofilaksis}

Proporsi responden alami kejadian kusta pada kelompok pernah mengalami luka terbuka sebesar 43,5\% < dibanding responden pada kelompok tidak pernah mengalami luka terbuka sebesar 56,5\%. Faktor riwayat pernah mengalami luka terbuka tidak berpengaruh terhadap kejadian kusta ( $\mathrm{p}=0,003$;OR: 0,47;95\%CI: 0,283-0,782) (Tabel 6).

\section{Kondisi ekonomi terhadap kejadian kusta pasca kemoprofilaksis}

Proporsi responden alami kejadian kusta pada kelompok pendapatan kurang sebesar 75,0\% > dibanding responden pada kelompok pendapatan tinggi sebesar $25,0 \%$. Faktor kondisi ekonomi keluarga berpengaruh terhadap kejadian kusta ( $\mathrm{p}=0,001 ; \mathrm{OR}: 3,31 ; 95 \% \mathrm{CI}: 1,930-5,660)$. Orang yang tergolong kondisi ekonomi keluarga berpendapatan kurang berisiko 3.31 kali tertular penyakit kusta dibandingkan orang yang kondisi ekonomi keluarga berpendapatan tinggi (Tabel 7). 
Kebersihan perorangan terhadap kejadian kusta pasca kemoprofilaksis

Proporsi responden mengalami kejadian kusta pada kelompok kebersihan perorangan buruk sebesar 73,4\%> dibanding dengan kelompok kebersihan perorangan baik sebesar 26,6\%. Faktor kebersihan perorangan berpengaruh terhadap kejadian kusta pasca kemoprofilaksis $(p=0,002 ; \mathrm{OR}: 2.35 ; \quad 95 \%$ CI:1,378-3,995). Orang yang tergolong kebersihan perorangan buruk berisiko 2,35 kali tertular penyakit kusta dibandingkan yang memiliki kebersihan perorangan baik (Tabel 8).

\section{Kondisi rumah terhadap kejadian kusta pasca kemoprofilaksis}

Proporsi responden alami kejadian kusta pada kelompok kondisi rumah tidak sehat sebesar $68,5 \%>$ dibanding responden pada kelompok kondisi rumah sehat sebesar 31,5\%. Faktor kondisi rumah tidak berpengaruh terhadap kejadian kusta pasca kemoprofilaksis( $\mathrm{p}=0,501 ; \mathrm{OR}: 1,20 ; 95 \%$ CI: 0,707-2,033) (Tabel 9).

Tabel 1. Tingkat pendidikan terhadap kejadian kusta pasca kemoprofilaksis

\begin{tabular}{|c|c|c|c|c|c|c|c|}
\hline \multirow{3}{*}{ Tingkat pendidikan } & \multicolumn{4}{|c|}{$\begin{array}{c}\text { Kejadian kusta pasca } \\
\text { kemoprofilaksis }\end{array}$} & \multirow{3}{*}{$\mathrm{p}$} & \multirow{3}{*}{ OR } & \multirow{3}{*}{$95 \% \mathrm{CI}$} \\
\hline & \multicolumn{2}{|c|}{ Kasus } & \multicolumn{2}{|c|}{ Kontrol } & & & \\
\hline & $\mathrm{f}$ & $\%$ & $\mathrm{n}$ & $\%$ & & & \\
\hline Rendah & 74 & 59,7 & 49 & 39,5 & & & \\
\hline Tinggi & 50 & 40,3 & 75 & 60,5 & 0,001 & 2,27 & $1,363-3,766$ \\
\hline Total & 124 & 100,0 & 124 & 100,0 & & & \\
\hline
\end{tabular}

Tabel 2. Kepatuhan minum obat terhadap kejadian kusta pasca kemoprofilaksis

\begin{tabular}{|c|c|c|c|c|c|c|c|}
\hline \multirow{3}{*}{$\begin{array}{c}\text { Kepatuhan minum } \\
\text { obat }\end{array}$} & \multicolumn{4}{|c|}{$\begin{array}{c}\text { Kejadian kusta pasca } \\
\text { kemoprofilaksis }\end{array}$} & \multirow{3}{*}{$\mathrm{p}$} & \multirow{3}{*}{ OR } & \multirow{3}{*}{$95 \% \mathrm{CI}$} \\
\hline & \multicolumn{2}{|c|}{ Kasus } & \multicolumn{2}{|c|}{ Kontrol } & & & \\
\hline & $\mathrm{f}$ & $\%$ & $\mathrm{n}$ & $\%$ & & & \\
\hline Tidak patuh & 64 & 51,6 & 49 & 39,5 & & & \\
\hline Patuh & 60 & 48,4 & 75 & 60,5 & 0,05 & 1,63 & $0,987-2,702$ \\
\hline Total & 124 & 100,0 & 124 & 100,0 & & & \\
\hline
\end{tabular}

Tabel 3. Lama kontak terhadap kejadian kusta pasca kemoprofilaksis

\begin{tabular}{|c|c|c|c|c|c|c|c|}
\hline \multirow{3}{*}{ Lama kontak } & \multicolumn{4}{|c|}{$\begin{array}{l}\text { Kejadian kusta pasca } \\
\text { kemoprofilaksis }\end{array}$} & \multirow{3}{*}{$\mathrm{p}$} & \multirow{3}{*}{ OR } & \multirow{3}{*}{$95 \% \mathrm{CI}$} \\
\hline & \multicolumn{2}{|c|}{ Kasus } & \multicolumn{2}{|c|}{ Kontrol } & & & \\
\hline & $\mathrm{f}$ & $\%$ & $\mathrm{n}$ & $\%$ & & & \\
\hline$\geq 1$ tahun & 92 & 74,2 & 69 & 55,6 & \multirow{3}{*}{0,002} & \multirow{3}{*}{2,29} & \multirow{3}{*}{$1,341-3,917$} \\
\hline$<1$ tahun & 32 & 25,8 & 55 & 44,4 & & & \\
\hline Total & 124 & 100,0 & 124 & 100,0 & & & \\
\hline
\end{tabular}


Tabel 4. Status vaksinasi BCG terhadap kejadian kusta pasca kemoprofilaksis

\begin{tabular}{|c|c|c|c|c|c|c|c|}
\hline \multirow{3}{*}{ Status vaksinasi BCG } & \multicolumn{4}{|c|}{$\begin{array}{c}\text { Kejadian kusta pasca } \\
\text { kemoprofilaksis }\end{array}$} & \multirow{3}{*}{$\mathrm{p}$} & \multirow{3}{*}{ OR } & \multirow{3}{*}{$95 \% \mathrm{CI}$} \\
\hline & \multicolumn{2}{|c|}{ Kasus } & \multicolumn{2}{|c|}{ Kontrol } & & & \\
\hline & $\mathrm{f}$ & $\%$ & $\mathrm{n}$ & $\%$ & & & \\
\hline Tidak ada parut BCG & 62 & 50,0 & 79 & 63,7 & & & \\
\hline Ada parut BCG & 62 & 50,0 & 45 & 36,3 & 0,029 & 0,57 & $0,343-0,947$ \\
\hline Total & 124 & 100,0 & 124 & 100,0 & & & \\
\hline
\end{tabular}

Tabel 5. Status gizi terhadap kejadian kusta pasca kemoprofilaksis

\begin{tabular}{lccccccc}
\hline & \multicolumn{9}{c}{ Kejadian kusta pasca } & & \\
\multirow{1}{*}{ Status gizi } & \multicolumn{2}{c}{ kemoprofilaksis } & \multirow{2}{*}{ OR } & 95\%CI \\
\cline { 2 - 5 } & \multicolumn{2}{c}{ Kasus } & \multicolumn{2}{c}{ Kontrol } & & & \\
\cline { 2 - 5 } & $\mathrm{f}$ & $\%$ & $\mathrm{n}$ & $\%$ & & & \\
\hline Buruk & 92 & 74,2 & 69 & 55,6 & & & \\
Baik (normal) & 32 & 25,8 & 55 & 44,4 & 0,001 & 4,68 & $2,725-8,022$ \\
\hline Total & 124 & 100,0 & 124 & 100,0 & & & \\
\hline
\end{tabular}

Tabel 6. Riwayat luka terbuka terhadap kejadian kusta pasca kemoprofilaksis

\begin{tabular}{lccccccc}
\hline & \multicolumn{3}{c}{ Kejadian kusta pasca } & & \\
Remoprofilaksis & \multirow{2}{*}{$\mathrm{p}$} & OR & 95\%CI \\
\cline { 2 - 5 } & \multicolumn{2}{c}{ Kasus } & \multicolumn{2}{c}{ Kontrol } & & & \\
\cline { 2 - 6 } & $\mathrm{f}$ & $\%$ & $\mathrm{n}$ & $\%$ & & & \\
\hline Pernah & 54 & 43,5 & 77 & 62,1 & & & \\
Tidak pernah & 70 & 56,5 & 47 & 37,9 & 0,003 & 0,47 & $0,283-0,782$ \\
\hline Total & 124 & 100,0 & 124 & 100,0 & & & \\
\hline
\end{tabular}

Tabel 7. Kondisi ekonomi terhadap kejadian kusta pasca kemoprofilaksis

\begin{tabular}{lccccccc}
\hline & \multicolumn{9}{c}{ Kejadian kusta pasca } & & \\
\multirow{2}{*}{ Kondisi ekonomi } & \multicolumn{3}{c}{ kemoprofilaksis } & \multirow{2}{*}{ OR } & 95\%CI \\
\cline { 2 - 5 } & \multicolumn{2}{c}{ Kasus } & \multicolumn{2}{c}{ Kontrol } & & & \\
\cline { 2 - 5 } & $\mathrm{f}$ & $\%$ & $\mathrm{n}$ & $\%$ & & & \\
\hline Pendapatan kurang & 93 & 75,0 & 59 & 47,6 & & & \\
Pendapatan tinggi & 31 & 25,0 & 65 & 52,4 & 0,001 & 3,31 & $1,930-5,660$ \\
\hline Total & 124 & 100,0 & 124 & 100,0 & & & \\
\hline
\end{tabular}

Tabel 8. Kebersihan perorangan terhadap kejadian kusta pasca kemoprofilaksis

\begin{tabular}{|c|c|c|c|c|c|c|c|}
\hline \multirow{3}{*}{$\begin{array}{l}\text { Kebersihan } \\
\text { perorangan }\end{array}$} & \multicolumn{4}{|c|}{$\begin{array}{l}\text { Kejadian kusta pasca } \\
\text { kemoprofilaksis }\end{array}$} & \multirow{3}{*}{$\mathrm{p}$} & \multirow{3}{*}{ OR } & \multirow{3}{*}{$95 \% \mathrm{CI}$} \\
\hline & \multicolumn{2}{|c|}{ Kasus } & \multicolumn{2}{|c|}{ Kontrol } & & & \\
\hline & $\mathrm{f}$ & $\%$ & $n$ & $\%$ & & & \\
\hline Buruk & 91 & 73,4 & 67 & 54,0 & & & \\
\hline Baik & 33 & 26,6 & 57 & 46,0 & 0,002 & 2,35 & $1,378-3,995$ \\
\hline Total & 124 & 100,0 & 124 & 100,0 & & & \\
\hline
\end{tabular}


Tabel 9. Kondisi rumah terhadap kejadian kusta pasca kemoprofilaksis

\begin{tabular}{lccccccc}
\hline & \multicolumn{9}{c}{ Kejadian kusta pasca } & & \\
\multirow{2}{*}{ Kondisi rumah } & \multicolumn{3}{c}{ kemoprofilaksis } & \multirow{2}{*}{ OR } & 95\%CI \\
\cline { 2 - 5 } & \multicolumn{2}{c}{ Kasus } & \multicolumn{2}{c}{ Kontrol } & & & \\
\cline { 2 - 5 } & $\mathrm{f}$ & $\%$ & $\mathrm{n}$ & $\%$ & & & \\
\hline Tidak sehat & 85 & 68,5 & 80 & 64,5 & & & \\
Sehat & 39 & 31,5 & 44 & 35,5 & 0,501 & 1,20 & $0,707-2,033$ \\
\hline Total & 124 & 100,0 & 124 & 100,0 & & & \\
\hline
\end{tabular}

\section{Analisis Multivariat}

Tabel 10. Rangkuman hasil analisis multivariat yang bermakna secara statistik

\begin{tabular}{clccccc}
\hline No & \multicolumn{1}{c}{ Variabel } & $\mathrm{B}$ & Wald & $\mathrm{p}$ & $\operatorname{Exp}(\mathrm{B})$ & $95 \% \mathrm{CI}$ for EXP (B) \\
\hline 1 & Tingkat pendidikan rendah & 0,665 & 4,959 & 0,026 & 1,94 & $1,083-3,490$ \\
\hline 2 & Lama kontak $\geq 1$ tahun & 0,719 & 5,183 & 0,023 & 2,05 & $1,105-3,813$ \\
\hline 3 & Status gizi buruk & 1,616 & 27,796 & 0,001 & 5,04 & $2,761-9,182$ \\
\hline 4 & $\begin{array}{l}\text { Kondisi ekonomi keluarga } \\
\text { berpendapatan kurang }\end{array}$ & 1,180 & 14,567 & 0,001 & 3,25 & $1,775-5,961$ \\
\hline 5 & $\begin{array}{l}\text { Kebersihan perorangan } \\
\text { buruk }\end{array}$ & 1,017 & 10,572 & 0,001 & 2,77 & $1,498-5,105$ \\
\hline & & & & & 0,050 & \\
\hline
\end{tabular}

\section{Pembahasan}

\section{Tingkat pendidikan terhadap kejadian kusta pasca kemoprofilaksis}

Faktor tingkat pendidikan rendah berpengaruh terhadap kejadian kusta ( $\mathrm{p}=0,026$, OR:1,94, 95\%CI: 1,083-3,490). Responden dengan tingkat pendidikan rendah berisiko 1,94 kali tertular kejadian kusta pasca kemoprofilaksis dibanding dengan tingkat pendidikan tinggi.

Penelitian yang dilakukan Pontes et $a l^{9}$ menemukan bahwa subjek yang berpendidikan rendah, pernah mengalami kekurangan makanan, kebiasaan mandi di badan air terbuka (sungai, danau, kolam) sehingga meningkatkan risiko penularan kusta di Brazil. Pada subjek yang berpendidikan rendah lebih berisiko mengalami kejadian kusta dibanding dengan subjek yang berpendidikan tinggi $\mathrm{OR}=2,05$ (95\% CI; 1,29-3,27). Keadaan ini dapat disebabkan oleh pengetahuan tentang penyakit kusta pada subjek yang berpendidikan tinggi dapat memahami mekanisme penularan kusta sehingga risiko kejadian kusta dapat dihindarkan.

\section{Lama kontak terhadap kejadian kusta pasca kemoprofilaksis}

Faktor lama kontak dengan penderita kusta $\geq 1$ tahun berpengaruh terhadap kejadian kusta pasca kemoprofilaksis $(p=0,023 ; \mathrm{OR}=2,05 ; 95 \% \mathrm{CI}=1,105-3,813)$. Job et $a l^{10}$ enemukan bahwa pada penderita kusta multibasiler yang belum diobati $80 \%$ ditemukan $M$. leprae di kulit dan $60 \%$ di mukosa hidung. Pada penelitian yang sama didapatkan hasil bahwa pada orang yang kontak serumah dengan penderita kusta $17 \%$ ditemukan $M$. leprae pada kulit dan $4 \%$ pada mukosa hidung. Dalam penelitian ini juga ditemukan bahwa 6(60\%) penderita kusta multibasiler yang sudah mendapatkan pengobatan dengan MDT masih ditemukan $M$. leprae pada kulit dan 
$4(40 \%)$ masih ditemukan M. leprae pada mukosa hidung. ${ }^{10}$

Mekanisme penularan kusta yang pasti belum diketahui, namun kedekatan kontak dengan penderita kusta diyakini bisa meningkatkan risiko kejadian kusta. Penelitian yang dilakukan oleh Noordeen pada tahun 1978 di India Selatan menemukan bahwa tinggal serumah dengan penderita kusta non-lepromatus meningkatkan risiko terkena kusta sebesar 9,5 kali. ${ }^{11}$ Semakin dekat hubungan keluarga dengan penderita kusta semakin tinggi risiko terkena kusta. Demikian juga dengan jarak tempat tinggal, semakin dekat bertetangga dengan penderita kusta semakin tinggi risiko menderita kusta. ${ }^{12}$

\section{Status gizi terhadap kejadian kusta pasca kemoprofilaksis}

Faktor status gizi buruk pada responden berpengaruh terhadap kejadian kusta $(\mathrm{p}=0,000 ; \mathrm{OR}=5,04 ; 95 \% \mathrm{CI}=2,761$ 9,182). Penyakit kusta banyak menyerang masyarakat dengan sosial ekonomi rendah. Hal ini dikaitkan dengan rendahnya daya tahan tubuh, gizi yang kurang baik dan lingkungan serta hygiene yang tidak baik. ${ }^{13}$

Faktor nutrisi dikatakan berperan dalam penularan M. leprae. Kejadian kusta tampak berkaitan dengan rendahnya produksi susu dan gandum. Menurut Berg, kondisi nutrisi sangat membaik pada pertengahan kedua abad 19, dan juga perbaikan pendapatan per kapita membuat populasi Norwegia lebih resisten terhadap infeksi M. leprae. ${ }^{14}$

\section{Kondisi ekonomi keluarga terhadap kejadian kusta pasca kemoprofilaksis}

Kondisi ekonomi keluarga yang berpendapatan kurang berpengaruh terhadap kejadian kusta $(\mathrm{p}=0,000$; $\mathrm{OR}=3,25 ; 95 \% \mathrm{CI}=1,775-5,96)$. Penelitian ini sejalan dengan hasil penelitian yang dilakukan Muharry di Kecamatan Tirto Kabupaten Pekalongan yang telah didiagnosis penderita kusta berdasarkan pemeriksaan klinis dan laboratorium. Sampel diambil berdasarkan fixed disease sampling. Hasil analisis multivariat menunjukkan bahwa faktor ekonomi keluarga yang rendah berpengaruh terhadap kejadian kusta $(\mathrm{p}=0,001$ dan $\mathrm{OR}=6,356 ; 95 \% \mathrm{CI}: 2,212-18,267){ }^{2}{ }^{2}$

Noorden ${ }^{13}$ menyebutkan faktor etnik, iklim, migrasi dan kondisi sosial ekonomi juga mempengaruhi penularan penyakit. Dikatakan bahwa sosial ekonomi rendah, kondisi rumah yang buruk dan terlalu padat berpengaruh terhadap penularan penyakit kusta. Rendahnya angka pasien baru di Eropa dihubungkan dengan perbaikan keadaan sosial ekonomi. ${ }^{13}$

Pendapatan merupakan salah satu faktor yang mempunyai peran dalam mewujudkan kondisi kesehatan seseorang. Pendapatan yang diterima seseorang akan mempengaruhi daya beli terhadap barangbarang kebutuhan lainnya seperti sandang dan papan. Seseorang dengan kondisi ekonomi keluarga rendah mempunyai risiko 6,356 kali lebih besar menderita kusta dibandingkan dengan seseorang yang kondisi ekonomi keluarganya baik. ${ }^{2}$

\section{Kebersihan perorangan terhadap kejadian kusta pasca kemoprofilaksis}

Faktor kebersihan perorangan yang buruk berpengaruh terhadap kejadian kusta $(\mathrm{p}=0,001$; OR $=2,77 ; 95 \% \mathrm{CI}=1,498$ $5,105)$. Hasil penelitian ini didukung oleh penelitian yang dilakukan Muharry ${ }^{2}$ di Kecamatan Tirto Kabupaten Pekalongan yang telah didiagnosis penderita kusta berdasarkan pemeriksaan klinis dan laboratorium. Sampel diambil berdasarkan fixed disease sampling. Hasil analisis multivariat menunjukkan faktor kebersihan perorangan buruk berpengaruh terhadap 
kejadian kusta $(\mathrm{p}=0,000$ dan $\mathrm{OR}=15,746$; $95 \% \mathrm{CI}=4,159-59,612)^{2}{ }^{2}$

Kebersihan perorangan adalah perawatan diri dari individu untuk mempertahankan kesehatannya yang dipengaruhi oleh nilai serta keterampilan. Di dalam dunia keperawatan, kebersihan perorangan merupakan kebutuhan dasar manusia yang harus senantiasa terpenuhi. Kebersihan perorangan termasuk dalam tindakan pencegahan primer yang spesifik. Kebersihan perorangan menjadi penting karena kebersihan perorangan yang baik akan meminimalkan pintu masuk (port of entry) mikroorganisme dan pada akhirnya mencegah seseorang terkena penyakit. ${ }^{15}$

\section{Status vaksinasi BCG terhadap kejadian kusta pasca kemoprofilaksis}

Hasil penelitian yang dilakukan oleh Haryadi dan Hardyanto ${ }^{16}$ di Kabupaten Brebes, Jawa Tengah pada analisis multivariat menunjukkan bahwa terdapat hubungan yang signifikan antara parut BCG dengan kejadian kusta (OR: 0,37; 95\% CI; 0,215-0,638). Faktor parut BCG melindungi (protektif) terhadap kejadian kusta sebesar 5,5\% dan Parut BCG memberi perlindungan terhadap kejadian kusta sebesar $63 \%$. $^{16}$

Bacille Calmette Guerin (BCG) dibuat dari satu strain dari Mycobacterium bovis yang dilemahkan. Vaksin ini digunakan utamanya untuk pencegahan terhadap penyakit yang disebakan oleh Mycobacterium tuberculosis (TBC). ${ }^{17}$ Pada akhir tahun 1930 muncul dugaan bahwa BCG juga mempunyai daya lindung terhadap penyakit kusta. Ditemukan bahwa vaksin BCG memberikan perlindungan terhadap kejadian kusta sebesar $80 \%$ pada kelompok umur 0-15 tahun di Uganda. Vaksinasi BCG juga dapat memberikan perlindungan sebesar $40 \%$ pada kelompok umur 0-4 tahun di Burma. Vaksinasi BCG memberikan perlindungan sebesar $46 \%$ di populasi dengan perlindungan tertinggi pada kelompok umur 5-14 tahun di Karimui. Vaksinasi BCG juga diketahui dapat melindungi seseorang dari terkena gejala klinis kusta antara $20-80 \%$ di berbagai tempat. ${ }^{18}$

\section{Riwayat luka terbuka terhadap kejadian kusta pasca kemoprofilaksis}

Faktor riwayat luka terbuka merupakan faktor protektif terhadap kejadian kusta pasca kemoprofilaksis $(\mathrm{p}=0,002 ; \mathrm{OR}=0,37 ; 95 \% \mathrm{CI}=0,200-0,699)$. M. leprae sering kali masuk melalui luka pada kulit yang terkontaminasi atau inokulasi dan melalui mukosa nasal. Responden merawat luka-luka pada kulit dengan teratur dan baik sehingga kecil kemungkinan untuk tertular kusta melalui luka terbuka. ${ }^{19}$

\section{Kondisi rumah terhadap kejadian kusta pasca kemoprofilaksis}

Faktor kondisi rumah pada uji bivariat tidak terbukti sebagai faktor risiko. ( $\mathrm{p}=0,501$;OR:1,20,95\%CI:0,707-2,033).

Kondisi rumah responden di Sampang sebagian besar masih semi permanen yang kebersihannya terjaga. Mereka memiliki budaya yang khas yaitu kamar mandinya terpisah dari rumah induk dengan alasan agar tidak mengundang rayap yang akan merusak konstruksi rumah, dan juga ada tersedia mushola-mushola sebagai tempat ibadah di setiap lingkungan mereka.

\section{Kesimpulan}

Faktor-faktor yang berpengaruh
terhadap kejadian kusta pasca
kemoprofilaksis yaitu tingkat pendidikan
rendah, lama kontak $\geq 1$ tahun, status gizi
buruk, kondisi ekonomi keluarga yang


berpendapatan kurang dan kebersihan perorangan buruk.

\section{Ucapan Terimakasih}

Terimakasih kepada masyarakat penderita kusta di Kabupaten Sampang, Jawa Timur yang bersedia menjadi obyek penelitian dan memberikan kontribusi dalam pengumpulan data.

\section{Daftar Pustaka}

1. Kemenkes RI.2016.Pedoman Nasional Program Pengendalian Penyakit Kusta. Jakarta: Kemenkes RI.

2. Muharry, A. 2014. Faktor Risiko Kejadian Kusta. Jurnal Kesehatan Masyarakat; 9(2): 174-182.

3. Blok, DJ., De Vlas, SJ., Richardus, JH. 2015.Global Elimination of Leprosy by 2020: Are We on Track?. Parasites\&Vectors;8:548.

4. Ferreira, SB., Yonekura, T., Takahashi, Ignotti, E.,Cortela, DCB., Soares, CB. 2015. RifampicinChemoprophylaxis in Preventing Leprosy in Contacts of Patients with Leprosy: A Comprehensive Systematic Review Protocol. JBI Database of Systematic Reviews \& Implementation Reports;13(2):84-100.

5. Departemen Kesehatan RI. 2004. Kantong Penderita Kusta Hambat Pencapaian Eliminasi Kusta.

6. Dinas Kesehatan Provinsi Jawa Timur. 2016. Analisa Situasi Program Pemberantasan Penyakit Kusta.

7. Dinas Kesehatan Provinsi Jawa Timur. 2016. Analisa Situasi Program Pemberantasan Penyakit Kusta Provinsi Jawa Timur.

8. Lemeshow, S., Hosmer Jr, DW., Klar, J., Lwanga, SK. Besar Sampel dalam Penelitian Kesehatan. Alih Bahasa Pramono, D. Yogyakarta: Gadjah
Mada University Press; 1997.pp.3235.

9. Pontes, LRS., Barreto, ML., Evangelista, CMN., Rodrigues, LC., Heukelbach, J., and Feldmeier, $\mathrm{H}$. Socioeconomic, Environmental, and Behavioural Risk Factors for Leprosy in North-East Brazil: Result of A CaseControl Study. International Journal of Epidemiology; 2006. Vol. 35:pp.9941000.

10. Joe, CK., Kumar, JJ., Kearney, M., Gillis, TP. 2008.Transmission of Leprosy: A Study of Skin and Nasal Secretions of Household Contacts of Leprosy Patients Using PCR. American Journal of Tropical Medicine and Hygiene.78(3)518-521.

11. Amirudin,MD., Hakim, Z., Darwis. 2003. E. Kusta: Diagnosis Penyakit Kusta, 2ed. Jakarta: Balai Penerbit FKUI.pp.12-31.

12. Moet, FJ., Pahan, D., Schoring, RO., Oscan, L., Richardus, J.H. 2006. Physical Distance Genetic Relationship Age and Leprosy Classification are Independent Risk Factor for Leprosy in Contacts of Patients with Leprosy. The Journal of Infectious Diseases.pp.193:346-353.

13. Noordeen, SK. 1994. The Epidemiology of Leprosy. Churchill Livingstone: In. Hasting RC. Leprosy, $2^{\text {nd }}$ edition.

14. Meima, A., Irgens, LM. 2002. Disappearance of Leprosy from Norway, An Explanation of Critical Factor Using An Epidemiological Modeling Approach. Int J Epid;31: 991-1000.

15. Manyullei, S., Utama, DA., Birawida, AB.2012.Gambaran Faktor yang Berhubungan dengan Penderita Kusta di Kecamatan Tamalate Kota Makassar. Indonesian Journal of Public Health;1(1).pp.10-17. 
16. Haryadi dan Hardyanto. 2011. Hubungan Status Vaksinasi BCG dengan Kejadian Kusta Di Kab.Brebes Provinsi Jawa Tengah. Pascasarjana Kesehatan Masyarakat/EL UGM.

17. Departemen Kesehatan. 2005. Buku Pedoman Nasional Pemberantasan Penyakit Kusta. Cetakan XVII. Jakarta: Direktorat Jendral PPM dan PLP.
18. Hariyadi, P. 2010. Hubungan Status Vaksinasi BCG dengan Kejadian Kusta di Kabupaten Brebes Provinsi Jawa Tengah. Tesis. Yogyakarta: Universitas Gadjah Mada.

19. Christiana, L. 2004. Lepra Subklinis dengan Pemeriksaan MLPA dan Faktor-faktor yang Mempengaruhi. Fakultas Kedokteran Universitas Diponegoro Semarang. 